\title{
Chemical and Physical Characterization of Stabilized Polyacrylonitrile (PAN) Fiber.
}

\author{
Shahrul Nizam Md Salleh ${ }^{1, \mathrm{a}}$, Mohamad Zaki Abdullah", ${ }^{2,}$, Azmi Abdul Wahab ${ }^{3}$, \\ 1,2,3 Mechanical Engineering Department,Universiti Teknologi PETRONAS, \\ Bandar Seri Iskandar, 31750 Tronoh, Perak,Malaysia
}

\begin{abstract}
Fibers Stabilization is an exothermic process which involves heat treatment at lower temperature from $150{ }^{\circ} \mathrm{C}$ to $300{ }^{\circ} \mathrm{C}$. It is considered as a crucial step that will determine the final structure of the carbon fibre and its mechanical properties. This work involves comparison of physical and mechanical properties of Polyacrylonitrile (PAN) and stabilized Polyacrylonitrile (PAN) fiber produced from batch process. The functional group of the fibre was studied using ATR-FTIR and the morphology was characterised by AFM and SEM. Mechanical properties of the fibers will be studies using single column tensile machine with ASTM D3822 testing procedure. The studies show significant change of physical and mechanical properties of Polyacrylonitrile (PAN) and stabilized Polyacrylonitrile (PAN) fiber. This lead to different application for every type of fibers produced before and after stabilization process.
\end{abstract}

\section{Introduction.}

Stabilisation is an exothermic process which involves heat treatment at lower temperature between 150 ${ }^{\circ} \mathrm{C}-300{ }^{\circ} \mathrm{C}$, carried out in an oxidative environment. It has been well reported that oxidative stabilisation of polyacrylonitrile (PAN) prior to carbonisation is the preferred route to production of high strength carbon fibres[1]. The process is normally facilitated in air as the incorporation of oxygen functionalities into the polymer backbone offers stability on the PAN ladder structure to withstand the subsequent high temperature $\left(1000^{\circ} \mathrm{C}-2000{ }^{\circ} \mathrm{C}\right)$ encountered during carbonisation.

Various competing reactions were suggested in the formation of a ladder like structure of the stabilised polymer, among them being cyclisation, dehydrogenation and oxidation (Figure 1). During stabilisation, cyclisation of the polymer is vital for the oxidation and incorporation of oxygen into the structure, in which the formation of the six-membered ring structure has been accepted as the main reaction. The nitrogen of the nitrile groups forms a bond with the carbon of the adjacent nitrile group in the polymer chain, producing $\mathrm{C}=\mathrm{N}$ conjugation in the structure and hence, the formation of the sixmembered ring [2]. The cyclisation process is initiated at several points of the PAN molecule during the heat treatment and grows until the end group reaches another cyclised unit. Dehydrogenation normally precedes cyclisation but often many authors would prefer a simultaneous reaction of both dehydrogenation and cyclisation. In the dehydrogenation process, the formation of $>\mathrm{C}=\mathrm{C}<$

${ }^{\text {a }}$ Corresponding author: shahruln@outlook.com

b Corresponding author: zaki_abdullah@petronas.com.my

This is an Open Access article distributed under the terms of the Creative Commons Attribution License 2.0, which permits unrestricted use, distribution, and reproduction in any medium, provided the original work is properly cited. 
conjugation in the polymer backbone contributes to a greater structure stability. During dehydrogenation, $\mathrm{HCN}$ and $\mathrm{NH}_{3}$ will be eliminated as the primary volatile by-product and this is thought to create an uncylised gaps in the polymer structure which could retard the process of cyclisation. In the presence of air in the stabilisation process which leads to oxidation process, various other compounds were suggested and these include nitrone, ketone, epoxide, lactone and lactam [3].

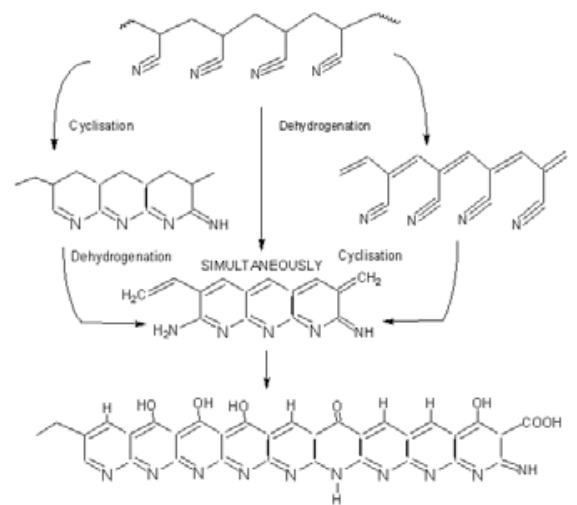

Figure 1. Chemical interactions that possibly took place during stabilisation in the process of ladder polymer formation during stabilisation process (Bahl et al., 1998).

\section{Experimental.}

PAN fibre produced by Fortafil Fibre Inc. with 320000 filament per tow was used in the study. Stabilisation for batch process is carried out in an oven (Memmert) at 2 different temperatures. The first temperature was carried out at $150{ }^{\circ} \mathrm{C}$ for 1 hours with heating rate of $5{ }^{\circ} \mathrm{C} / \mathrm{min}$. While the other temperature was set at $250{ }^{\circ} \mathrm{C}$ for 1 hours with heating rate of $5{ }^{\circ} \mathrm{C} / \mathrm{min}$

\subsection{Physico-Chemical Characterisation.}

The changes in the functional groups of the PAN fibre were detected using the Fourier Transform Infra-Red (FTIR) (Nicolet FT-IR Spectrometer 2000). The transmittance spectra were collected using the ATR-FTIR at a resolution of $4 \mathrm{~cm}^{-1}$ and 360 scans. Scanning Electron Microscope (SEM) (LEO Supra) was used to determine the morphology of the PAN fibre and the reduction in fibre diameter throughout the heat treatment process. Atomic force microscope (AFM) was used to determine surface topography of the stabilized PAN fibers.

\subsection{Mechanical Characterization.}

Mechanical testing was carry out using single column tensile machine with $5000 \mathrm{~N}$ load. Standard Test Method for Tensile Properties of Single Textile Fibers, ASTM D3822 was preloaded in the machine setting. Comparison was done to PAN fibers with heated in two different temperature region.

\section{Result and Discussion.}

$150{ }^{\circ} \mathrm{C}$ was chosen due to preliminary stage of stabilization process. At this temperature, the colour of the fibers was change from white to yellowish. Starting from $200{ }^{\circ} \mathrm{C}$ and above, the colour of the fibers 
was black. Thus it is interesting to study and compare physical and chemical behaviour produced fibers from these two temperature zone. Commercially available PAN fibers have different additive an copolymer,therefore every PAN fibers have different range of stabilization zone between $150^{\circ} \mathrm{C}$ and $300{ }^{\circ} \mathrm{C}$. In this study, $250{ }^{\circ} \mathrm{C}$ was selected because there is a save zone before precarbonization at above $300{ }^{\circ} \mathrm{C}$ occured. A Differential scanning calorimetry (DSC) study should be conducted to determine exact stabilization temperature range.

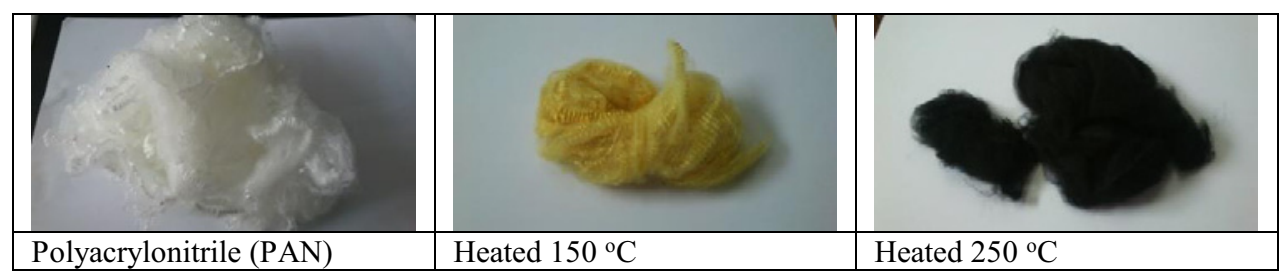

Figure 2. Color comparison of stabilized fibers

\subsection{Fourier Transform Infra-Red (FTIR)}

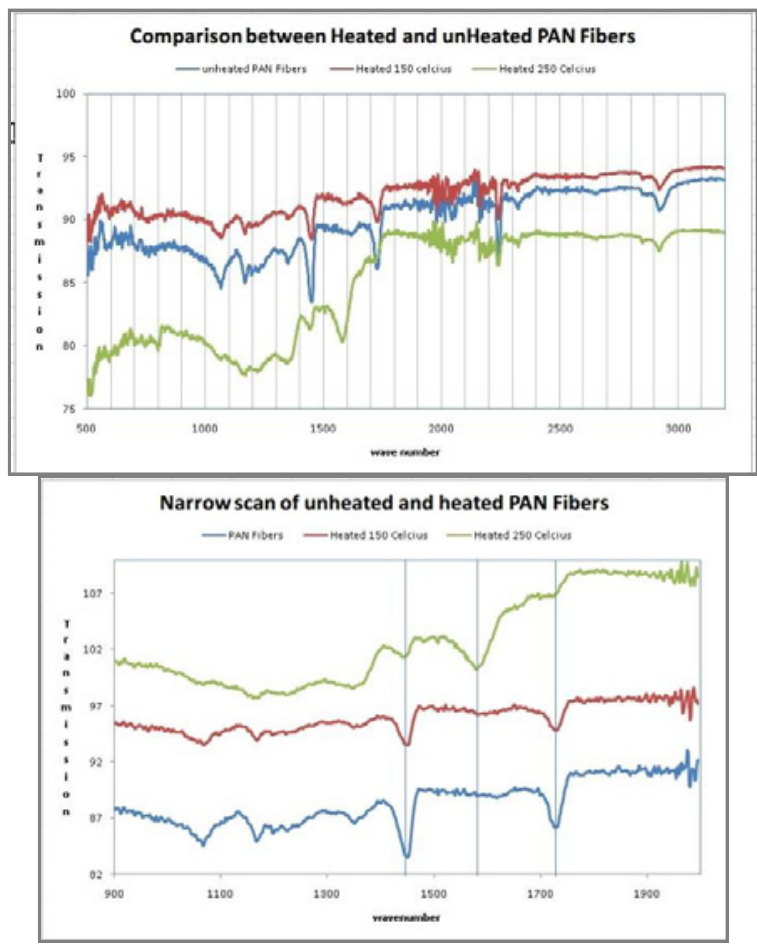

Figure 3. Overall and narrow FTIR spectrum of unheated and heated PAN fibers

Figure 3 showed the existing functional group of PAN fibre before and after the heat treatment. Overall spectrum showed almost similar spectrum except in region 900 to $2000 \mathrm{~cm}^{-1}$ as shown in figure 3. In figure 3, $2240 \mathrm{~cm}^{-1}$ of cyanide $(-\mathrm{C} \equiv \mathrm{N})$ which is main functional group of PAN fibers gradually decrease in concentration when heated to $250^{\circ} \mathrm{C}$. In figure 3 , it is clearly shown the existing of a new peak in $1580 \mathrm{~cm}^{-1}$ region after heat treated to $250{ }^{\circ} \mathrm{C} .1580 \mathrm{~cm}^{-1}$ was referred to double bonding of carbon $(\mathrm{C}=\mathrm{C})$ exist in cyclic form. The double bond only exists when heat treated in 250 
${ }^{\circ} \mathrm{C}$. This suggests that intermolecular or intramolecular cross-linking might have taken place forming the cyclisation reaction. For $1725 \mathrm{~cm}^{-1}$, indicate the existent of carbonyl group in PAN fibers and was gradually decreased with increasing temperature. The carbonyl group was found in PAN fibers due to commoner exist in the polymer which is a common for PAN fibers manufacturing process in order to increase the plasticity effect to the fibers. Compound Methyl acrylate was often used as commoner in PAN polymer to produce the fibers.Peak 1070 and $1170 \mathrm{~cm}^{-1}$ also show decrease in intensity from before and after heat treatment. This shows ether (R-0-R) functional group in the comonomer degrade before cyclisation process begun.

\subsection{Scanning Electron Microscope(FTIR).}

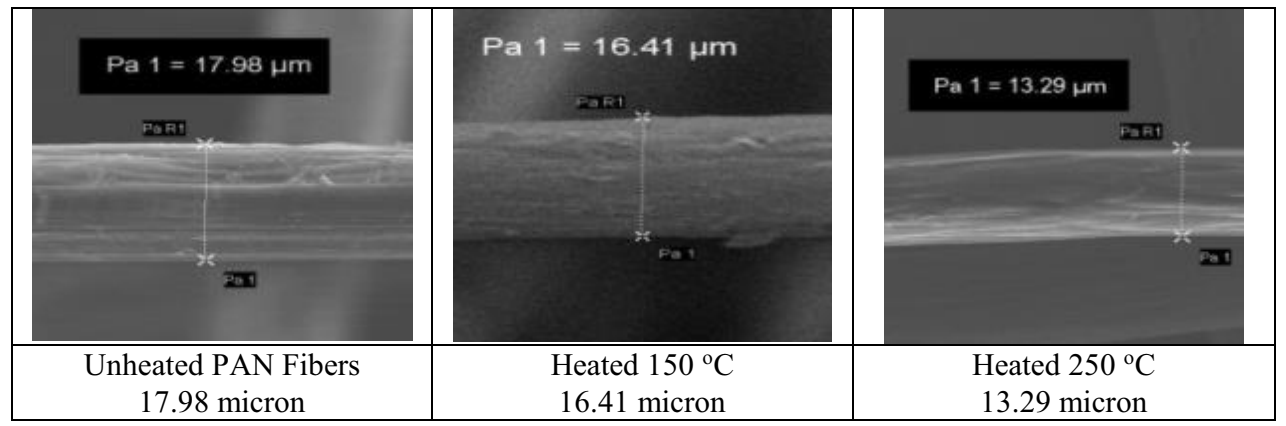

Figure 4. PAN Fibers surface topography using Atomic Force Microscope.

Scanning Electron Microscopy (SEM) image show steady diameter decrease from and after heat treated. Surface morphology show PAN fibers surface relatively became smoother after heat treated. Roughness of the surface can be shown by AFM results.

\subsection{Atomic Force Microscope(AFM).}

\begin{tabular}{|c|c|c|c|}
\hline Topography image & & \\
& & \\
\hline
\end{tabular}

Figure 5. PAN Fibers surface topography using Atomic Force Microscope.

An atomic Force Microscopy study shows surface topography before and after heat treatment. Before heat treatment. Root mean square (RMS) roughness shown the degres value from $125.873 \mathrm{~nm}$ to 84.98. This is because the PAN fibers before heat treatment contain impurity on the surface of the fibers after spinning process to produce the fibers.

\subsection{Mechanical Characterization}

The unheated and heated samples were mechanical test using single column tensile machine with $5000 \mathrm{~N}$ load. The average breaking force showed in Table 1 . The test was conducted according to 
ASTM D3822 Test Method for Tensile Properties of Single Textile Fibers [4] with jig suitable for the test method.

Table 1. Comparison of PAN fibers before and after heat treated.

\begin{tabular}{|c|c|c|c|c|}
\hline PAN Fibers & $\begin{array}{l}\text { Tensile } \\
\text { Strength } \\
\left(\mathbf{N} / \mathbf{m m}^{2}\right)\end{array}$ & $\begin{array}{c}\text { Breaking } \\
\text { Force }(\mathbf{c N})\end{array}$ & $\begin{array}{c}\text { Initial } \\
\text { modulus } \\
(\mathbf{c N} / \text { tex })\end{array}$ & $\begin{array}{c}\text { Elongation } \\
\mathbf{( \% )}\end{array}$ \\
\hline $\mathrm{O}^{\circ} \mathrm{C}$ & 2.05 & 74062 & 1520 & 195. \\
\hline $150^{\circ} \mathrm{C}$ & 1.49 & 48935 & 1524 & 270 \\
\hline $250^{\circ} \mathrm{C}$ & 0.93 & 24979 & 1118 & 133 \\
\hline
\end{tabular}

According to ASTM D3822 Initial modulus was defined as the ratio of the change in stress, expressed in centi newton per tex (cN/tex) or gram-force per denier ( $\mathrm{gf} / \mathrm{den})$, to the change in strain, expressed as a fraction of the original length. Breaking force was defined as maximum force applied to a material carried to rupture observed and generally expressed as millinewton $(\mathrm{mN})$ or gram-force. Elongation was defined as the ratio of the extension of a material to the length of the material prior to stretching, expressed as a percent. The mechanical properties of stabilized PAN fibers degrade compare to PAN Fibers. This is due to insertion of oxygen molecules that assist the cyclization on arylonitrile monomer to form graphitic carbon ring structure. The intermolecular reaction weaken the structure of stabilized fibers due to molecular rearrangement inside the fibers.

\section{Summary}

From the result, stabilization process starting from $150^{\circ} \mathrm{C}$ significantly shows chemical and mechanical change of the fibers. At $250{ }^{\circ} \mathrm{C}$ zone, FTIR spectra show cyclization reaction start to occur. SEM and AFM reveals decreased in diameter and surface roughness due to shrinkage and removal of impurities on the surface of the fibers by heat treatment process. However the strength of the fibers has significantly dropped from the original PAN fibers strength due to insertion of oxygen to assist cyclization process. Oxidative stabilization usually are varied between $150{ }^{\circ} \mathrm{C}$ to $300{ }^{\circ} \mathrm{C}$ and depend on commoner add into the PAN fibers. Different manufacturer have their own formulation to produce the PAN fibers. To determine precise oxidative temperature range, Differential Scanning Calorimetry (DSC) should be conducted. In this experiment, PAN fibers heated in $250{ }^{\circ} \mathrm{C}$ was in stabilization zone. However if the heat treatment was conducted above the stabilization zone without inert environment, the fibers will degrade into black carbon and lost its fibers properties. Stabilized PAN fibers can be used as fire resistant product because of thermally stable, exhibit excellent resistance to chemicals and solvents and are electrically nonconductive behavior.

\section{References}

1. P.J. Sánchez-Soto, M.A. Avilés, J.C. del Río, J.M. Ginés, J. Pascual, J.L. Pérez-Rodríguez, Thermal study of the effect of several solvents on polymerization of acrylonitrile and their subsequent pyrolysis, J. Anal. Appl. Pyrolysis 59, 155-172 (2001).

2. X. Huang, Fabrication and properties of carbon fibers, Materials 2, 2369-2403 (2009).

3. T.-H. Ko, S.-C. Liau, M.-F. Lin, Preparation of graphite fibres from a modified PAN precursor, J. Mater. Sci. 27, 6071-6078 (1992).

4. L. Jie, Z. Wangxi, Structural changes during the thermal stabilization of modified and original polyacrylonitrile precursors, J. Appl. Polym. Sci. 97, 2047-2053(2005). 